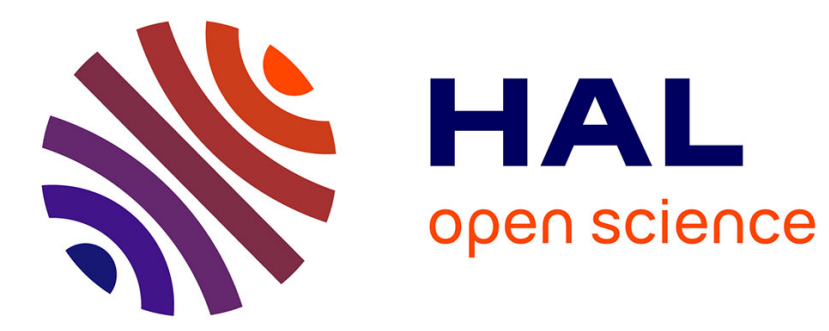

\title{
Complementary variable- and person-centered approaches to the dimensionality of burnout among fire station workers
}

Emilie Sandrin, Alexandre J S Morin, Claude Fernet, Nicolas Gillet

\section{- To cite this version:}

Emilie Sandrin, Alexandre J S Morin, Claude Fernet, Nicolas Gillet. Complementary variable- and person-centered approaches to the dimensionality of burnout among fire station workers. Anxiety, Stress and Coping, In press, 10.1080/10615806.2021.1959917 . hal-03322859

\section{HAL Id: hal-03322859 \\ https://hal.science/hal-03322859}

Submitted on 19 Aug 2021

HAL is a multi-disciplinary open access archive for the deposit and dissemination of scientific research documents, whether they are published or not. The documents may come from teaching and research institutions in France or abroad, or from public or private research centers.
L'archive ouverte pluridisciplinaire HAL, est destinée au dépôt et à la diffusion de documents scientifiques de niveau recherche, publiés ou non, émanant des établissements d'enseignement et de recherche français ou étrangers, des laboratoires publics ou privés. 
Running Head: Burnout Dimensionality and Profiles

\title{
Complementary Variable- and Person-Centered Approaches to the Dimensionality of Burnout Among Fire Station Workers
}

\author{
Emilie Sandrin $^{1 *}$, Alexandre J. S. Morin ${ }^{2 *}$, Claude Fernet ${ }^{3}$, and Nicolas Gillet ${ }^{1,4}$ \\ ${ }^{1}$ QualiPsy EE 1901, Université de Tours, Tours, France \\ ${ }^{2}$ Substantive-Methodological Synergy Research Laboratory, Concordia University, Montreal, \\ Québec, Canada \\ ${ }^{3}$ LIPROM, Université du Québec à Trois-Rivières, Trois-Rivières, Québec, Canada \\ ${ }^{4}$ Institut Universitaire de France (IUF)
}

* Since the first two authors (E.S. \& A.J.S.M.) contributed equally to the preparation of this article, their order was determined at random: Both should be considered first authors.

Correspondence concerning this article should be addressed to Nicolas Gillet, Université de Tours, UFR-Arts et Sciences Humaines, Département de psychologie, 3 rue des Tanneurs, 37041 Tours Cedex 1, France. E-mail: nicolas.gillet@univ-tours.fr.

This is the prepublication version of the following manuscript:

Sandrin, E., Morin, A. J. S, Fernet, C., \& Gillet, N. (in press). Complementary variable- and person-centered approaches to the dimensionality of burnout among fire station workers. Anxiety, Stress, \& Coping. Early view. https://doi.org/ 10.1080/10615806.2021.1959917

(C) 2021. This paper is not the copy of record and may not exactly replicate the authoritative document published in Anxiety, Stress, \& Coping. 


\begin{abstract}
This research relies on variable- and person-centered approaches to illustrate how each of these approaches may help to improve our understanding of the dimensionality of the burnout construct. Both studies (Study 1: $N=247$ administrative and technical employees; Study 2: $N=654$ firefighters), showed that employees' burnout ratings simultaneously reflected a global overarching construct co-existing with two specific dimensions (cynicism and emotional exhaustion), with a distinct factor reflecting reduced professional efficacy. In Study 1, perceived supervisor recognition and job satisfaction were associated with lower levels of global burnout levels. In Study 2, we examined the configurations, or profiles, taken by burnout dimensions (global burnout, specific cynicism, specific emotional exhaustion, and reduced professional efficacy), and documented associations between these profiles and four covariates (organizational, supervisor, and colleagues recognition as well as job satisfaction). Five profiles were identified using latent profile analyses: Very Low Burnout Risk, Mentally Distanced, Low Burnout Risk, High Burnout Risk, and Moderately High Burnout Risk. Employees' perceptions of supervisor and colleagues recognition were related to their likelihood of profile membership. Employees' job satisfaction levels also differed as a function of their profile.
\end{abstract}

Key words: Burnout; latent profiles; recognition; job satisfaction; firefighters; bifactor models 


\section{Introduction}

There is a general recognition (Maslach et al., 2001) that a comprehensive assessment of burnout should tap into the three components of emotional exhaustion, cynicism, and reduced professional efficacy. These components are seen as independent (Maslach et al., 2001), and prior meta-analyses have supported that each of these three components shared unique associations with covariates (Alarcon, 2011). However, research has suggested that employees could also experience burnout as a single global construct (Schaufeli \& Enzmann, 1998). This global representation is supported by the high correlations reported among ratings of the three burnout components (Maslach et al., 2001), and by the presence of stronger associations with covariates when burnout is defined as a global dimension (Shirom \& Melamed, 2006).

Unfortunately, these prior investigations have not relied on an operationalization of burnout allowing them to differentiate employees' global $(\mathrm{G})$ and specific $(\mathrm{S})$ levels of burnout, raising a series of potentially critical questions regarding: (a) whether the burnout facets of emotional exhaustion, cynicism, and reduced professional efficacy really retain meaningful specificity beyond the assessment of the overarching burnout construct; and (b) whether this overarching construct exists as a G-entity including specificities mapped by the facets, or whether these facets reflect distinct correlated dimensions without such a common core (Morin et al., 2017). Indeed, recent research relying on a bifactor approach has shown that burnout ratings could be simultaneously represented by a G-level across all facets and by S-levels of emotional exhaustion, cynicism, and reduced professional efficacy left unexplained by this G-level (e.g., Hawrot \& Koniewski, 2018; Isoard-Gautheur et al., 2018).

Despite the interest of this improved bifactor representation, the criterion-related validity of the resulting G/S components of burnout remains insufficiently explored. Fortunately, alternative variable- (e.g., Isoard-Gautheur et al., 2018) and person- (Leiter \& Maslach, 2016) centered approaches exist to support a more thorough investigation of these important 
questions. The present research illustrates these approaches while contributing to research on burnout by: (a) relying on the variable-centered bifactor modeling framework to account for the multidimensionality of this construct (Studies 1 and 2); (b) relying on person-centered analyses to assess the nature of employees' burnout profiles while taking into account the G/S components (Study 2); and (c) documenting the criterion-related validity of the G/S dimensions (Study 1) and profiles (Study 2) by examining their associations with covariates (organizational, supervisor, and colleagues recognition as well as job satisfaction).

\section{Co-Existing Global and Specific Burnout Components}

Hawrot and Koniewski (2018) found support for a bifactor model of burnout including one G-factor and three S-factors (emotional exhaustion, cynicism, and reduced professional efficacy). However, their results revealed low reliability for the three S-factors. Mészáros et al. (2014) and Szigeti et al. (2017) reported similar conclusions, showing that the burnout Gfactor and the reduced professional efficacy S-factor were the main sources of variation in item scores. Researchers have also suggested that a two-factor model including only emotional exhaustion and cynicism might be more appropriate, based on methodological and conceptual rationales, challenging the relevance of the reduced professional efficacy component (Kalliath et al., 2000). Additional studies are needed to confirm that enough specificity exists at the subscale level once G-levels of burnout are considered, and to document the role of reduced professional efficacy as independent, or not, from G-levels of burnout.

\section{Study 1}

Study 1 was designed to investigate the multidimensionality of a measure of burnout. To document the value of considering employees' S-levels of emotional exhaustion, cynicism, and reduced professional efficacy beyond their G-levels of burnout, we also consider the criterionrelated validity of this solution by examining relations between these components and a series of covariates (organizational, supervisor, and colleagues recognition as well as job satisfaction). 
Recognition refers to the way the organization, supervisors, and colleagues show their appreciation and acknowledge the efforts and successes of employees (Fall, 2015). It can be shown by the spontaneous acknowledgment of work well done, by expressing consideration towards the staff, and by words of encouragement in difficult situations (Sandrin et al., 2019). We focus on recognition from different sources (i.e., organization, supervisor, and colleagues) based on the acknowledgement that providing professional recognition to workers represents a costeffective way to maintain and improve employees' well-being and performance (e.g., Fernet et al., 2012). According to the job demands-resources model, recognition at work can be conceptualized as an important resource for employees, suggesting that it should help workers to regulate their short-term fatigue and recover more optimally from work, and thus to avoid burnout (Bakker \& de Vries, 2021). Prior research has demonstrated negative associations between recognition (or similar constructs) and indicators of ill-being at work, including burnout (Caesens et al., 2014, 2020; Sandrin et al., 2019). For these reasons, we expected organizational, supervisor, and colleagues support to be associated with lower G-levels of burnout and with lower S-levels of emotional exhaustion, cynicism, and reduced professional efficacy. Job satisfaction was also considered given its documented association with work performance and organizational retention (e.g., Bowling, 2007). Research reveals negative associations between job satisfaction and burnout (Huyghebaert et al., 2017), so that highly satisfied employees can often be described as fulfilled and happy. We thus expected job satisfaction to be associated with lower G-levels of burnout and S-levels of emotional exhaustion, cynicism, and reduced professional efficacy.

\section{Method}

\section{Participants and Procedure}

This study relies on a sample of 247 administrative and technical employees (71 men and 176 women) working in various fire stations located in France. Most participants worked full time (89.1\%). Respondents were aged between 24 and 63 years $(M=43.3, S D=8.5)$, had an 
average tenure in their organization of 13.7 years $(S D=7.7)$, and had an average tenure in their position of 8.6 years $(S D=6.2)$. This study follows the principles of the Declaration of Helsinki. All participants received an e-mail explaining the study purpose and inviting them to complete an online questionnaire. Once online, participants were first asked to complete a consent form emphasizing the anonymous and voluntary nature of their participation.

\section{Measures}

Burnout. Participants completed the 15-item version of the Maslach Burnout InventoryStudent Survey (MBI-SS; Portoghese et al., 2018) adapted to the work context. This instrument assesses emotional exhaustion (5 items; e.g., "I feel used up at the end of a day at work"; $\alpha=.90$ ), cynicism (4 items; e.g., "I doubt the significance of my work"; $\alpha=.71$ ), and reduced professional efficacy (6 items; e.g., "At work, I feel confident that I am effective in getting things done"; $\alpha=.74$; all of these items were reversed coded prior to the analyses). All items were rated on a seven-point response scale ranging from 0 (never) to 6 (always).

Recognition. Organizational (5 items; e.g., "My organization offers me chances of promotion"; $\alpha=.79$ ), supervisor (5 items; e.g., "My supervisor encourages me when I am confronted with a difficult task"; $\alpha=.91$ ), and colleagues (4 items; e.g., "My colleagues congratulate me or thanks me for good work"; $\alpha=.92$ ) recognition were measured on a fivepoint scale ("Strongly Disagree" to "Strongly Agree") using Fall’s (2015) scale.

Job satisfaction. Job satisfaction was assessed with one-item (Shimazu et al., 2015; i.e., "Are you satisfied with your job?") rated on a 1 (dissatisfied) to 4 (satisfied) scale.

\section{Analyses}

Analyses were conducted using the Maximum Likelihood Robust (MLR) estimation in Mplus 8 (Muthén \& Muthén, 2018). Missing responses at the item level (0\% to 30.4\%; $M=$ 5.3\%) were handled using Full Information Maximum Likelihood (FIML; Enders, 2010). Preliminary analyses were conducted to verify the psychometric properties of all measures. 
Burnout models were estimated using bifactor-confirmatory factor analyses (bifactor-CFA; Morin et al., 2017). This decision is based on evidence supporting the superiority of bifactor models for burnout measures (e.g., Hawrot \& Koniewski, 2018; Isoard-Gautheur et al., 2018). Independent CFA factors reflecting the recognition measure and the single-item job satisfaction measure were then added to the bifactor solution to estimate the criterion-related validity of the burnout factors using latent correlations. Model adequacy was checked using goodness-of-fit indices, where values $>.90$ and .95 on the Tucker-Lewis index (TLI) and the comparative fit index (CFI), and values lower than .08 and .06 on the root mean square error of approximation (RMSEA) were respectively taken to reflect acceptable and excellent levels of fit (e.g., Marsh et al., 2005).

\section{Results and Discussion}

\section{Preliminary Analyses: Burnout}

The a priori bifactor-CFA resulted in a satisfactory level of fit $\left(\chi^{2}=121.21, \mathrm{df}=75, \mathrm{p} \leq\right.$ $.01, \mathrm{CFI}=.96 ; \mathrm{TLI}=.94 ; \mathrm{RMSEA}=.05)$, and an improvement relative to the CFA $\left(\chi^{2}=\right.$ $160.36, \mathrm{df}=87, \mathrm{p} \leq .01, \mathrm{CFI}=.93 ; \mathrm{TLI}=.94 ; \mathrm{RMSEA}=.06)$. For the CFA, the results revealed reliable factors that were well-defined by a majority of their indicators (see Table 1). However, they also revealed a high correlation between the cynicism and emotional exhaustion factor $(r=.51)$, but an almost null correlation between the reduced professional efficacy factor and the emotional exhaustion $(r=-.02)$ and cynicism $(r=-.03)$ factors. These correlations argue against the need to incorporate a G-factor, as least in relation to ratings of reduced professional efficacy. Supporting this idea, the bifactor-CFA results revealed a burnout G-factor that was well-defined by all of the emotional exhaustion items, moderately well-defined by the cynicism items, but weakly defined by the reduced professional efficacy items, suggesting that these items might tap into a different construct.

We thus estimated an alternative bifactor-CFA encompassing cynicism and emotional 
exhaustion but including a distinct correlated CFA factor reflecting reduced professional efficacy. This alternative solution resulted in an equally satisfactory level of fit $\chi^{2}=123.32$, $\mathrm{df}=78, \mathrm{p} \leq .01, \mathrm{CFI}=.96 ; \mathrm{TLI}=.94 ; \mathrm{RMSEA}=.05)$, and in reliable burnout $\mathrm{G}-$ and professional efficacy CFA factors, a moderately reliable cynicism S-factor, and a weakly defined emotional exhaustion S-factor. This alternative bifactor solution was thus retained. This decision was also anchored in a similar examination of the results obtained in Study 2, reported in the online supplements, which converge on a similar solution. The measurement invariance of this solution across studies was also supported. Parameter estimates (reported in the online supplements) from the most invariant solution suggests that when both studies are considered, more specificity remains in the emotional exhaustion S-factor than in the cynicism S-factor, supporting our decision to retain both S-factors in both studies.

\section{Preliminary Analyses: Recognition}

The results also support the adequacy of the model underlying the recognition measure $\left(\chi^{2}\right.$ $=126.80, \mathrm{df}=74, \mathrm{p} \leq .01, \mathrm{CFI}=.97 ; \mathrm{TLI}=.96 ; \mathrm{RMSEA}=.05)$, as well as that of the combined models encompassing burnout (the alternative bifactor-CFA solution) and recognition $\left(\chi^{2}=498.16, \mathrm{df}=350, \mathrm{p} \leq .01, \mathrm{CFI}=.95 ; \mathrm{TLI}=.94 ; \mathrm{RMSEA}=.04 ;\right.$ RMSEA CI $=.03$ to .05$)$. The parameter estimates from this solution are reported in Table $\mathrm{S} 1$ in the online supplements and revealed well-defined factors for all constructs.

\section{Correlations (Criterion-Related Validity)}

Latent correlations are reported in Table 2. As hypothesized and in line with past studies (Huyghebaert et al., 2017; Sandrin et al., 2019), the three sources of recognition and job satisfaction were negatively related to the burnout G-factor. Organizational, supervisor, and colleagues recognition were associated with lower levels of reduced professional efficacy (i.e., higher levels of professional efficacy). Colleagues recognition was associated with lower S-levels of cynicism. These results thus support associations involving both the G- and the S- 
factors of burnout. In the next study, we relied on latent profile analyses (LPA) to examine the combined effects of all four components of burnout in a more holistic manner.

\section{Study 2}

This study documents the burnout profiles that characterize employees. These profiles are estimated while jointly considering G-levels of burnout and S-levels of emotional exhaustion and cynicism, as well as reduced professional efficacy as a distinct factor. To ascertain the construct validity of these profiles (Morin \& Litalien, 2019), we more specifically consider their criterion-related validity. First, we adopt a multivariate perspective to identify the unique associations between each source of recognition (relative to all others) and the likelihood of profile. Second, we conduct mean-level comparisons of job satisfaction across profiles.

\section{Burnout Profiles}

Person-centered research has started to look at how burnout components combine within employees (e.g., Berjot et al., 2017; Portoghese et al., 2018). However, many previous studies have relied on a combination of burnout components and other variables as profile indicators (work engagement: Mäkikangas et al., 2017; psychological distress and satisfaction with life: Laverdière et al., 2018), making it impossible to isolate the effects of burnout. Among studies focusing solely on burnout, Berjot et al. (2017) identified four profiles based on the emotional exhaustion, cynicism, and reduced professional efficacy components (Maslach et al., 2001). However, this study is limited by its reliance on a sample of psychologists, so that additional studies are needed to generalize these findings to other occupations. Likewise, Leiter and Maslach (2016) identified five burnout profiles among two samples of health-care workers. More generally, the nature, number, and range of burnout indicators considered in prior studies are quite large (professional inefficacy, cynicism, physical and emotional exhaustion, guilt, etc.). These studies have also relied on a variety of samples (psychologists, teachers, mixed samples, etc.), methods (cross-sectional and longitudinal), and covariates. This variety 
makes it hard to achieve a clear integration of results. Yet, despite these differences, the results seem to converge on the following profiles: (a) High Burnout Risk; (b) Moderately High Burnout Risk; (c) Moderately Low Burnout Risk; and (d) Low Burnout Risk. However, person-centered evidence emerges from an accumulation of research, making it possible to distinguish core profiles emerging systematically from those who occur only in some contexts, and from those reflecting sample-specific idiosyncrasies.

In addition, all of these studies have relied on indicators ignoring the dual G/S nature of burnout. This limitation is important. When applying person-centered analyses to indicators known to present a $\mathrm{G} / \mathrm{S}$ structure, relying on indicators unable to properly disaggregate these components results in the erroneous estimation of profiles characterized by matching levels across indicators, thereby reflecting only G-levels of burnout and ignoring specificities located at the subscale level (Morin et al., 2016a, 2017). The present study addresses this limitation by documenting burnout profiles defined based on $\mathrm{G} / \mathrm{S}$ levels of burnout.

Lacking prior guidance from person-centered research in which the multidimensional G/S nature of employees' burnout ratings were properly disaggregated, we leave as an open question the structure and number of profiles that will best reflect burnout profiles. Nevertheless, in alignment with the consistency of the aforementioned findings, it seems reasonable to assume that some profiles will display a High Burnout Risk (high G-levels of burnout across indicators), Moderate Burnout Risk (average levels of burnout across indicators), and Low Burnout Risk (low G-levels of burnout across indicators) configuration. Conversely, in accordance with a subset of shape-differentiated profiles obtained in burnout research (Berjot et al., 2017; Leiter \& Maslach, 2016) and with the added value of the approach adopted in the present study to achieve a better disaggregation of G/S levels of burnout (Morin et al., 2016a, 2017), it also seems reasonable to expect the identification of additional profiles characterized by more differentiated configurations. 


\section{Construct Validation}

A critical step in the assessment of the construct validity of profiles, especially when relying on a predominantly inductive approach such as the one used here to identify the profiles (Morin et al., 2018) is to document their theoretical and practical implications via the examination of associations between profile membership and theoretically-relevant covariates (Morin \& Litalien, 2019). In Study 2, we extend the results obtained in Study 1 by a consideration of the same set of covariates. This matching consideration is important given that person-centered analyses are generally described as providing the flip side of the coin from variable-centered analyses (Morin et al., 2018). More precisely, the fact that isolated facets of burnout (e.g., exhaustion S-factor) shared no relation, on their own, with this set of covariates in Study 1 does not exclude the possibility that these facets might play a role in profile definition and, in doing so, in driving associations between profile membership and these covariates.

Despite the importance of recognition at work, no person-centered research has examined the associations between organizational, supervisor, and colleagues recognition and burnout profiles. However, findings from Study 1 and prior research (Fernet et al., 2012; Sandrin et al., 2019) suggest that lower levels of organizational, supervisor, and colleagues recognition should be associated with a higher probability of membership into profiles presenting higher G-levels of burnout (e.g., High Burnout Risk). Likewise, although we expect well-differentiated associations between the burnout profiles and job satisfaction, the lack of previous personcentered studies relying on a proper disaggregation of the G/S components of burnout, or even considering the associations between job satisfaction and these profiles, precludes the formulation of precise hypotheses. However, Study 1 and prior variable-centered studies have reported negative relations between burnout components and job satisfaction (Huyghebaert et al., 2017). As a result, we hypothesize that profiles presenting higher G-levels of burnout (e.g., 
High Burnout Risk) should be characterized by lower levels of job satisfaction relative to profiles presenting lower G-levels of burnout (e.g., Low Burnout Risk).

\section{Method}

This study relies on a sample of 654 firefighters (598 men and 56 women) working in various French fire stations. Most participants worked full time (87.5\%). Respondents were aged between 21 and 63 years $(M=41.1, S D=8.3)$, had been working as firefighters for an average of 21.5 years $(S D=8.4)$, and had an average tenure in their position of 5.7 years $(S D$ $=4.9)$. Procedures and measures were identical to those used in Study 1. Scale score reliability estimates were as follow: (a) emotional exhaustion $(\alpha=.89)$; (b) cynicism ( $\alpha=$ .70); (c) reduced professional efficacy $(\alpha=.67)$; (d) organizational recognition $(\alpha=.79)$; (e) supervisor recognition $(\alpha=.93)$; and (f) colleagues recognition $(\alpha=.90)$.

\section{Analyses}

As in Study 1, all analyses were realized using Mplus 8 (Muthén \& Muthén, 2018), MLR estimation, and FIML to handle missing data ( $0 \%$ to $2.3 \% ; M=0.54 \%)$.

\section{Preliminary Analyses}

As in Study 1, preliminary factor analyses were conducted to verify the psychometric properties of all measures (supporting the conclusions from Study 1) and their measurement invariance across samples used in Studies 1 and 2. Due to the complexity of the measurement invariance models underlying all constructs, these preliminary analyses were conducted separately for the burnout and recognition measures. Factor scores were saved from the most invariant measurement models and used as inputs for the main analyses (for a discussion of the advantages of factor scores in LPA, see Morin et al., 2016a, b). Conclusions from these analyses matched those from Study 1 (see the online supplements for the results). Latent correlations are reported in Table 2, and converge on results similar to those from Study 1, with the main exception that the emotional exhaustion S-factor was negatively related to all 
covariates in Study 2, possibly due to its higher level of specificity in Study 2.

\section{Model Estimation and Selection}

LPA were estimated using 5000 random sets of start values, 1000 iterations, and 200 final optimizations (Hipp \& Bauer, 2006). We examined solutions including one to eight profiles in which the means and variances of the burnout factors were freely estimated in all profiles (Peugh \& Fan, 2013). To select the optimal number of profiles, we considered theoretical conformity, meaning, and statistical adequacy of the solutions (Morin \& Litalien, 2019). Statistical indices are also available to guide this decision. Thus, lower values on the Bayesian Information Criterion (BIC), sample-size Adjusted BIC (ABIC), Akaïke Information Criterion (AIC), and Consistent AIC (CAIC) indicate a better fitting model. In addition, a statistically significant pvalue associated with the adjusted Lo, Mendell, and Rubin's (2001) Likelihood Ratio Test (aLMR) and the Bootstrap Likelihood Ratio Test (BLRT) supports the added value of a solution when contrasted with a solution including one less profile. Statistical studies support the accuracy of the CAIC, BIC, ABIC, and BLRT, but not that of the AIC and aLMR (e.g., Diallo et al., 2017; Peugh \& Fan, 2013). We thus only report these indicators (AIC and aLMR) for complete disclosure, not to guide model selection. All indicators remain influenced by sample size and so often keep on suggesting adding profiles without converging on a specific solution (Marsh et al., 2009). In this situation, the point at which the decrease in the value of these indicators reaches a plateau, on a graphical elbow plot, suggests the optimal solution (Morin et al., 2011). Finally, the entropy (from 0 to 1) indicates the precision with which the cases are classified into the various profiles, but should not be used to guide model selection.

\section{Criterion-Related Validity}

Associations between recognition and profile membership were assessed via multinomial logistic regressions. The three sources of recognition were directly (i.e., the one-step approach) integrated into the LPA solution to examine the unique associations between each 
source of recognition (relative to all others) and the likelihood of profile membership via a multinomial logistic regression link function. Two models were contrasted (Diallo et al., 2017). First, the associations between recognition and profile membership were fixed to be zero (null effect models). Second, these associations were freely estimated. However, prior to the integration of recognition, preliminary models were estimated, following the same sequence, to assess the need to incorporate demographic controls: Sex, age, tenure as a firefighter, tenure in the current position, education level, employment schedule, marital situation, and children. Alternative models were contrasted using the information criteria (AIC, CAIC, BIC, and ABIC; Morin et al., 2016b). Finally, job satisfaction levels were contrasted across pairs of profiles using a model-based approach (Lanza et al., 2013) implemented via the Auxiliary (DCON) function (Asparouhov \& Muthén, 2014) allowing for the comparison of latent profiles (i.e., corrected for classification error) without allowing job satisfaction to change the nature of the profiles (Marsh et al., 2009).

\section{Results and Discussion}

\section{Latent Profile Analyses (LPA)}

The fit of the LPA solutions is reported in Table 4, and the elbow plot is reported in Figure $\mathrm{S} 1$ of the online supplements. The CAIC reached its lowest point at six profiles, whereas the BIC, ABIC, and BLRT failed to converge on a solution. The elbow plot shows a plateau in the decrease of the various information criteria somewhere between four and six profiles. Solutions including four, five, and six latent profiles were thus examined. This examination revealed that they were statistically proper and that, up to five profiles, each increase resulted in the addition of a meaningful profile to the solution. In contrast, adding a sixth profile resulted in the arbitrary division of an existing profile into smaller ones $(\leq 2 \%)$ with a similar shape. Thus, the five-profile solution was retained. This model is illustrated in Figure 1. The results reveal a high level of classification accuracy of participants into their most likely 
profiles (see Table S5 in the online supplementary materials), ranging from $83.4 \%$ to $94.1 \%$ across profiles, consistent with the high entropy value associated with this solution (.76).

\section{Profile Description}

Profile 1 characterized employees with very low G-levels of burnout coupled with moderately low S-levels of cynicism, low S-levels of emotional exhaustion, and low levels of reduced professional efficacy. This Very Low Burnout Risk profile corresponded to $3.9 \%$ of the employees. Profile 2 characterized employees presenting average G-levels of burnout coupled with high S-levels of cynicism, moderately low S-levels of emotional exhaustion, and low levels of reduced professional efficacy. This Mentally Distanced profile corresponded to $25.6 \%$ of the employees. Profile 3 characterized employees with low G-levels of burnout coupled with low levels of reduced professional efficacy, moderately low S-levels of cynicism, and average S-levels of emotional exhaustion. This Low Burnout Risk profile corresponded to $13.4 \%$ of the employees. Profile 4 characterized employees presenting high G-levels of burnout coupled with average S-levels of emotional exhaustion and cynicism, and average levels of reduced professional efficacy. This High Burnout Risk profile corresponded to $42.4 \%$ of the employees. Finally, Profile 5 characterized employees presenting moderately high G-levels of burnout coupled with high levels of reduced professional efficacy, average Slevels of emotional exhaustion, and low S-levels of cynicism. This Moderately High Burnout Risk profile corresponded to $14.8 \%$ of the employees.

\section{Recognition and Profile Membership}

As shown in Table 4, the analyses involving the demographic controls supported the null effect model, suggesting a lack of associations between demographic variables and profile membership. These variables were thus excluded from further analyses. In contrast, the results supported the presence of associations between recognition and profile membership (see Table 5). These associations seemed to be primarily driven by colleagues recognition, 
followed by supervisor recognition, with organizational recognition showing no evidence of sharing associations with profile membership. In accordance with our expectations (Fernet et al., 2012; Sandrin et al., 2019), colleagues recognition was associated with a higher likelihood of membership in all profiles relative to Profile 5 (Moderately High Burnout Risk), as well as into Profile 1 (Very Low Burnout Risk) relative to Profiles 2 (Mentally Distanced), 3 (Low Burnout Risk), and 4 (High Burnout Risk). In addition, supervisor recognition was associated with a higher likelihood of membership into Profile 3 (Low Burnout Risk) relative to Profiles 2 (Mentally Distanced), 4 (High Burnout Risk), and 5 (Moderately High Burnout Risk).

\section{Job Satisfaction and Profile Membership}

Our results revealed that levels of job satisfaction varied significantly across profiles. More precisely, levels of job satisfaction (on a 1 to 4 rating scale), together with their $95 \%$ confidence intervals $(\mathrm{CI})$, observed in each profile were as follow: Profile 1 (Very Low Burnout Risk): $M=2.97$ (CI $=2.75$ to 3.19); Profile 2 (Mentally Distanced $): M=2.88(\mathrm{CI}=$ 2.79 to 2.97); Profile 3 (Low Burnout Risk): $M=2.93$ (CI = 2.81 to 3.05); Profile 4 (High Burnout Risk): $M=2.65$ (CI = 2.58 to 2.73); and Profile 5 (Moderately High Burnout Risk): $M=2.33(\mathrm{CI}=2.17$ to 2.48$)$. In terms of statistical significance, these results revealed that the levels of job satisfaction were the highest in Profiles 1 (Very Low Burnout Risk), 2 (Mentally Distanced), and 3 (Low Burnout Risk), which did not differ from one another, followed by Profile 4 (High Burnout Risk), and finally by Profile 5 (Moderately High Burnout Risk) which displayed the lowest levels of job satisfaction of all profiles. In line with Study 1, these results confirm that job satisfaction was negatively related to G-burnout (Huyghebaert et al., 2017).

\section{General Discussion}

This research adopted a dual variable- and person-centered approach, advocated by Morin et al. (2017), to analyze the value of jointly considering G/S dimensions of the burnout construct. Through the application of this framework, we were able to achieve an improved 
representation of the structure of employees' burnout measurement and profiles.

\section{Multidimensionnality of Burnout}

In Studies 1 and 2, results supported a bifactor representation of burnout across two independent samples of employees. This solution revealed co-existing factors representing Glevels of burnout and S-factors reflecting levels of cynicism and emotional exhaustion left unexplained by this G-factor. The burnout G-factor and the S-cynicism factor were both welldefined by most of their indicators, supporting the idea that ratings of cynicism contributed to the assessment of G-levels of burnout while retaining specificity unrelated to these G-levels. In contrast, the emotional exhaustion S-factor was more weakly defined, suggesting that ratings of emotional exhaustion mainly served to define G-levels of burnout without retaining a lot of unicity. These results reinforce the idea that cynicism and emotional exhaustion are the core dimensions of burnout (Schaufeli \& Enzmann, 1998), while ratings of cynicism also incorporate additional information (Isoard-Gautheur et al., 2018).

Finally, this solution revealed that reduced professional efficacy was best reflected as an independent factor, rather than as contributing to the assessment of participants' G-levels of burnout. This observation is consistent with tentative empirical evidence showing that ratings of reduced professional efficacy did not seem to share very strong associations with G-levels of burnout (Hawrot \& Koniewski, 2018; Szigeti et al., 2017). It also supports prior theoretical arguments calling into question the relevance of this so-called third dimension of burnout (Kalliath et al., 2000). Nevertheless, as suggested by Cherniss (1983), professional efficacy may also represent a protective personal resource against burnout. Indeed, employees who feel confident in having the skills necessary to successfully perform their tasks are more likely to display low levels of burnout (Skaalvik \& Skaalvik, 2010). Alternatively, reduced professional efficacy may also be an outcome of burnout, as employees experiencing burnout (i.e., a prolonged state of resource depletion) are less likely to restore their personal resources, 
leading to lower levels of professional efficacy (Kim \& Burić, 2020). Further studies are needed to clarify these issues and to achieve a more nuanced understanding of the links between reduced professional efficacy and the G/S facets of burnout.

In terms of criterion-related validity (a component of the construct validation process), Study 1 revealed that the relations between organizational, supervisor, and colleagues recognition and the burnout components mainly involved employees' G-levels of burnout and reduced professional efficacy. These results support prior research showing that perceived organizational, supervisor, and colleagues recognition were negatively related to employees' G-levels of burnout and to reduced professional efficacy (Fernet et al., 2012; Sandrin et al., 2019). However, higher levels of colleagues recognition were associated with lower S-levels of cynicism, suggesting that additional associations involving the burnout S-factors also exist. These results suggest that it is unwarranted to assume that the associations between perceived organizational, supervisor, and colleagues recognition are similar acros all components of burnout. These results match those from previous studies showing that the role of different sources of recognition differs as a function of the variables considered (Caesens et al., 2020).

Having a similar work experience, it might be easier or more natural for a colleague to appreciate the value and meaning of the effort invested and to share enthusiasm about the work to be done. Indeed, colleagues may have a vested interest in supporting the individual's ability to stay and get well by facilitating psychological detachment from their work (S-levels of cynicism net of G-levels of burnout) as this dimension is known to be strongly related to citizenship behaviors and group performance (Hunter \& Wu, 2016). Assuming equal levels of recognition from the organization, supervisor, and colleagues, colleagues recognition may be more valued as a resource than organizational and supervisor recognition because of the greater frequency to which employees interact with their colleagues. Sharing a comparable work experience, colleagues may have a greater propensity to judge not only the quantity, but 
also the quality of the task to be performed. Because of the importance of instrumental and emotional recognition, colleagues may also be more inclined to offer recognition, and it might be easier for them to do so, to employees with whom they interact on a daily basis.

Results also supported our expectations (Huyghebaert et al., 2017) by revealing a negative association between job satisfaction and G-levels of burnout. However, they also went against our expectations (Kalliath et al., 2000; Leiter \& Maslach, 2016) in failing to reveal significant associations between job satisfaction and S-levels of emotional exhaustion and cynicism, as wel as with reduced professional efficacy. Although these results call into question the need to consider these components once employees' G-levels of burnout are considered, we more thoroughly verified this assertion via the adoption of a person-centered approach in Study 2.

\section{Burnout Profiles}

The results showed that five profiles best summarized the burnout configurations observed in Study 2. These profiles generally met our expectations and matched results from personcentered studies (Berjot et al., 2017; Leiter \& Maslach, 2016) while allowing us to separately consider the role played by G/S burnout components, a distinction which was ignored in these previous studies. This similarity highlights the robustness of our results and the utility of interventions focused on employees' profiles. Likewise, the results also reinforce the value of jointly considering the G- and S- (cynicism and emotional exhaustion) facets of burnout, coupled with an independent reduced professional efficacy dimension. The similarity across studies relying on different approaches, measures, and operationalizations (i.e., traditional versus $\mathrm{G} / \mathrm{S}$ ) supports the idea that these profiles tap into meaningful psychological processes, just as differences and specificities in results support the unicity of the burnout construct.

\section{Recognition and Burnout Profiles}

The present results revealeld strong associations between supervisor and colleagues recognition and profile membership, lending additional support to previous research showing 
the beneficial role of these two job resources for employees (Fernet et al., 2012; Sandrin et al., 2019). In alignment with Study 1, supervisor recognition was associated with a higher likelihood of membership into the Low Burnout Risk profile relative to the Mentally Distanced, High Burnout Risk, and Moderately High Burnout Risk profiles. Also aligned with Study 1, perceived colleagues recognition was first associated with a lower likelihood of membership into one of the least desirable profile (Moderately High Burnout Risk) relative to all other profiles. Colleagues recognition was also associated with a higher likelihood of membership into the most desirable Very Low Burnout Risk profile relative to the Mentally Distanced, Low Burnout Risk, and High Burnout Risk profiles, supporting previous reports of negative associations between perceived colleagues recognition and burnout (Peterson et al., 2008). These findings reinforce the role played by colleagues recognition noted in Study 1.

Many theoretical arguments have been proposed to account for the benefits of colleagues and supervisor recognition. Thus, some have noted that employees involved in high-quality relationships with their colleagues and supervisors were more likely to be trusted by their peers and managers and thus allowed a greater level of autonomy (Caesens et al., 2020). Likewise, positive relationships between colleagues and supervisors have also been proposed to elicit positive affective responses during social interactions, to reduce stress-evoking uncertainties or conflicts in the work environment through the availability of informative communication flows, and to generate more positive self-perceptions (Fall, 2015).

Conversely, and contrasting with the results obtained in Study 1 in which this source of work recognition displayed strong associations with employees' G-levels of burnout when considered in isolation, perceptions of organizational recognition showed no evidence of associations with profile membership. As already suggested, such results support the idea that perceived organizational, supervisor, and colleagues recognition may be differently related to burnout components (Caesens et al., 2014, 2020; Fall, 2015). In fact, these results go even 
further in suggesting the benefits of combining high levels of supervisor and colleagues recognition to ensure that G-levels of burnout remain low. However, they also suggest that perceived organizational recognition may not be as effective at decreasing employees' likelihood of membership into the most problematic burnout profiles, despite circumstantial evidence of variable-centered associations shared with G-levels of burnout when considered on their own. This is interesting given that the bulk of prior research has positioned perceived organizational recognition as a positive driver of work-related functioning in a the more, the better perspective (e.g., Caesens et al., 2014; Fall, 2015). Our findings might suggest a more nuanced view of perceived organizational recognition in line with prior variable-centered results revealing curvilinear relations between perceived organizational support and employees' functioning (e.g., Harris \& Kacmar, 2018). More specifically, these studies demonstrated that the most adaptive functioning tended to be associated with moderate to moderately high levels of perceived organizational support.

It is possible that moderate levels of perceived organizational recognition coupled with high levels of perceived colleagues and supervisor recognition might decrease the likelihood of membership into the profiles characterized by the highest G-levels of burnout. In addition, high levels of perceived colleagues and supervisor recognition might be the prerogative of employees able to benefit from perceived organizational recognition. These hypotheses are in line with recent findings showing that high levels of perceived supervisor support may coexist with low levels of perceived organizational support, that employees may display a profile characterized by high levels of perceived organizational, supervisor, and colleagues support, and that this latter profile may be associated with the most positive functioning (Caesens et al., 2020). This interpretation also helps to make sense of the apparent discrepancy in results obtained across Studies 1 and 2 in relation to the role played by organizational recognition. These results encourage scholars to further examine the distinct 
and complementary role of perceived organizational, supervisor, and colleagues recognition.

\section{Job Satisfaction and Profile Membership}

Our results finally revealed differentiated associations between the burnout profiles and job satisfaction. Employees who had average to very low G-levels of burnout (Very Low Burnout Risk, Low Burnout Risk, and Mentally Distanced) displayed higher levels of job satisfaction than Moderately High Burnout Risk and High Burnout Risk employees. These findings are consistent with our hypotheses and with prior results revealing that workers presenting high G-levels of burnout tend to experience tiredness and reduced functional capacity, which in turn seem associated with a higher likelihood of maladaptive functioning (Alarcon, 2011).

However, not all profiles differed on job satisfaction in a way that matched our expectations (Huyghebaert et al., 2017). For instance, the levels of job satisfaction observed in the Very Low Burnout Risk and Low Burnout Risk profiles were impossible to differentiate from those observed in the Mentally Distanced profile. This observation suggests that high S-levels of cynicism may not necessarily be harmful on their own. Leiter and Maslach (2016) also showed that their Disengaged profile (characterized by high levels of cynicism) was not associated with the lowest levels of job satisfaction. It is important to keep in mind that the interpretation of a S-factor taken from a bifactor model differs from that of a first-order factor. In a bifactor model, S-factors reflect levels of imbalance in employees' cynicism relative to their G-levels of burnout across all dimensions. Thus, this S-factor reflects a feeling of cynicism that is not backed by a matching feeling of emotional exhaustion. This S-factor might be taken to reflect a type of detachment toward work, as an adaptive way to preserve a sense of purpose, once disaggregated from employees' G-levels of burnout. In line with the protective role of S-cynicism observed in the present research, numerous studies have shown that psychological detachment (i.e., the ability to stop thinking about work-related matters during off-job time; Sonnentag \& Fritz, 2015) is associated with positive functioning. The 
inability to stop thinking about work has the effect of maintaining employees' psychological systems in a state of activation, thus prohibiting recovery. In contrast, psychological detachment may help to turn off these systems, thus supporting recovery from accumulated work-related energy expenditure (see Sonnentag \& Fritz, 2015, for a review).

Similarly, the lowest levels of job satisfaction observed in the Moderately High profile characterized by high levels of reduced professional efficacy and low S-levels of cynicism suggest that professional efficacy and S-cynicism may possibly play a protective role against low levels of job satisfaction. Supporting this interpretation, the results also showed that levels of job satisfaction were higher in the High Burnout Risk profile than in the Moderately High Burnout Risk profile, which presented a configuration opposite to that of the Mentally Distanced profile in displaying low levels of cynicism coupled with high levels of reduced professional efficacy. Clearly, the cynicism/detachment-professional inefficacy combination does seem to play a particularly important role when the job satisfaction of employees with moderate to high G-levels of burnout is considered. Overall, our results confirm the utility of accounting for $\mathrm{G} / \mathrm{S}$ facets of burnout coupled with the independent reduced professional efficacy factor when contrasting burnout profiles in relation to covariates. Additional studies considering a broader range of positive (e.g., performance, organizational citizenship behaviors) and negative (e.g., absenteeism, counterproductive behaviors) indicators of work functioning are needed to better understand the mechanisms underlying these relations.

\section{Practical Implications}

From an intervention perspective, our findings demonstrate that managers should be attentive to employees exposed to, or rather perceiving being exposed to, low levels of recognition at work, and even more importantly low levels of supervisor recognition. Indeed, our results showed that these workers were more likely to experience higher G-levels of burnout and lower levels of job satisfaction. Consequently, changes designed to increase 
supervisor recognition sustainably might decrease burnout in the long run. Among possible ways to achieve this objective, supervisors might promote a supportive culture, for instance, by promoting fairness in the application of policies (Caesens et al., 2020). Informal mentoring and social events might also help to build a stronger support climate among employees (Newman et al., 2012). The endpoint of these strategies is to create a workplace characterized by supportive and positive interactions among colleagues, subordinates, and supervisors.

In terms of research implications, this research represents a first step toward the identification of the most commonly observed burnout configurations. However, more research is needed to systematically understand the work-related characteristics at play in the emergence of these profiles, as well as the additional occupational groups among which those profiles might emerge more frequently (Morin et al., 2016b). For instance, previous research has revealed variations in burnout as a function of work settings, job design, or emotional demands (Huyghebaert et al., 2018b; Sandrin et al., 2019), making it important to verify whether the identified profiles will generalize across work contexts.

Moreover, the present findings add to mounting research evidence supporting the value of adopting a bifactor representation of burnout ratings (Hawrot \& Koniewski, 2018; IsoardGautheur et al., 2018). They showcase the importance of adequately accounting for the dual G/S nature of burnout, separated from a distinct factor reflecting reduced professional efficacy. Indeed, researchers and practitioners relying on more classical operationalizations of burnout (e.g., scale scores, CFA) ignore the globality/specificity accounted for in a bifactor model. This is likely to mistakenly suggest that the cynicism and emotional exhaustion facets of burnout are reasonably distinct constructs without a common core and yet displaying comparable associations with covariates (Morin et al., 2016a, 2017). This erroneous conclusion would stem from the unmodelled role of the G-factor, and obscure the equally important role played by S-burnout components. Ignoring this duality will thus result in a 
biased, and far more limited, view of the complex reality of the burnout construct.

To avoid burnout estimates reflecting a confusing mixture of $\mathrm{G} / \mathrm{S}$ variance likely to be tainted by multicollinearity, researchers and practitioners are thus invited to consider adopting a bifactor representation of burnout ratings. This recommendation strongly advocates in favor of a latent variable approach to research. Yet, this recommendation is easy to transpose to the professional context where practitioners and organizations may still want to manually score burnout questionnaires. In these contexts, the present results suggest the need to develop automated scoring procedures relying on calculations similar to those involved in the generation of the factor scores used in the present research (Morin et al., 2016a, 2017). Yet, this consideration reinforces the importance for future research to rely on more representative samples prior to the development of any practically-useful scoring procedure.

\section{Limitations and Future Directions}

The present research has some limitations. First, this research capitalized on self-report measures, which may have been influenced by self-reported biases and social desirability. Furthermore, it relied on an adapted version of a questionnaire initially developed for students to assess burnout (the MBI-SS) rather than tools directly created for the assessment of work burnout. However, it would be interesting for future studies to investigate the replicability of our results using alternative measures of burnout. Likewise, upcoming studies should incorporate more objective indicators of organizational and individual functioning (e.g., absenteeism), as well as ratings obtained from multiple informants (e.g., supervisors' ratings of performance). Second, this research involved two samples of administrative and technical employees, and firefighters. Other variable- and person-centered studies are still needed to confirm the generalizability of the results demonstrated here and their associations with a broader range of covariates across a variety of countries, cultures, and occupations (e.g., teachers, sales employees, managers) (Morin et al., 2016b). 
Third, although we considered associations between burnout dimensions and profiles and a variety of covariates (i.e., organizational, supervisor, and colleagues recognition, as well as job satisfaction), our cross-sectional design did not allow us to assess the directionality of these associations, nor to consider spurious associations, reversed causality, or reciprocal influence. Consequently, additional longitudinal research would gain from studying the direction of the relations between predictors, outcomes, and burnout. Finally, it would be worthwhile for future studies to consider a greater variety of work-related (e.g., leadership behaviors) or individual (e.g., perfectionism, job crafting) dimensions that may increase or decrease the likelihood of membership in burnout profiles.

\section{References}

Alarcon, G.M. (2011). A meta-analysis of burnout with job demands, resources, and attitudes. Journal of Vocational Behavior, 79, 549-562. https://doi.org/10.1016/j.jvb.2011.03.007

Asparouhov, T., \& Muthén, B. (2014). Auxiliary variables in mixture modeling: Three-step approaches using Mplus. Structural Equation Modeling, 21, 329-341. https://doi.org/10.1080/10705511.2014.915181

Bakker, A.B., \& de Vries, J.D. (2021). Job Demands-Resources theory and self-regulation: New explanations and remedies for job burnout. Anxiety, Stress, \& Coping, 34, 1-21. https://doi.org/10.1080/10615806.2020.1797695

Berjot, S., Altintas, E., Grebot, E., \& Lesage, F.-X. (2017). Burnout risk profiles among French psychologists. Burnout Research, 7, 10-20. https://doi.org/10.1016/j.burn.2017.10.001

Bowling, N.A. (2007). Is the job satisfaction-job performance relationship spurious? Journal of Vocational Behavior, 71, 167-185. https://doi.org/10.1016/j.jvb.2007.04.007

Caesens, G., Gillet, N., Morin, A.J.S., Houle, S.A., \& Stinglhamber, F. (2020). A person- centred perspective on social support in the workplace. Applied Psychology: An 
International Review, 69, 686-714. https://doi.org/10.1111/apps.12196

Caesens, G., Stinglhamber, F., \& Luypaert, G. (2014). The impact of work engagement and workaholism on well-being: The role of work-related social support. Career Development International, 19, 813-835. https://doi.org/10.1108/CDI-09-2013-0114

Cherniss, C. (1993). Role of professional self-efficacy in the etiology and amelioration of burnout. In W.B. Schaufeli, C. Maslach, \& T. Marek (Eds.), Professional burnout: Recent developments in theory and research (pp. 135-149). Taylor \& Francis.

Diallo, T.M.O, Morin, A.J.S., \& Lu, H. (2017). The impact of total and partial inclusion or exclusion of active and inactive time invariant covariates in growth mixture models. Psychological Methods, 22, 166-190. https://doi.org/10.1037/met0000084

Enders, C.K. (2010). Applied missing data analysis. Guilford.

Fall, A. (2015). [Recognition at work: Validation of a measuring scale in the context of companies]. European Review of Applied Psychology, 65, 189-203. https://doi.org/10.1016/j.erap.2015.07.001

Fernet, C., Austin, S., \& Vallerand, R.J. (2012). The effects of work motivation on employee exhaustion and commitment: An extension of the JD-R model. Work \& Stress, 26, 213-229. https://doi.org/10.1080/02678373.2012.713202

Harris, K.J., \& Kacmar, K.M. (2018). Is more always better? An examination of the nonlinear effects of perceived organizational support on individual outcomes. The Journal of Social Psychology, 158, 187-200. https://doi.org/10.1080/00224545.2017.1324394

Hawrot, A., \& Koniewski, M. (2018). Factor structure of the Maslach Burnout InventoryEducators Survey in a Polish-speaking sample. Journal of Career Assessment, 26, 515530. https://doi.org/10.1177/1069072717714545

Hipp, J.R., \& Bauer, D.J. (2006). Local solutions in the estimation of growth mixture models. Psychological Methods, 11, 36-53. https://doi.org/10.1037/1082-989X.11.1.36 
Hunter, E.M., \& Wu, C. (2016). Give me a better break: Choosing workday break activities to maximize resource recovery. Journal of Applied Psychology, 101, 302-311. https://doi.org/10.1037/ap10000045

Huyghebaert, T., Gillet, N., Becker, C., Kerhardy, S., \& Fouquereau, E. (2017). Examining the effect of affective commitment to the supervisor on nurses' psychological health as a function of internal locus of control. Journal of Nursing Management, 25, 297-306. https://doi.org/10.1111/jonm.12466

Isoard-Gautheur, S., Martinent, G., Guillet-Descas, E., Trouilloud, D., Cece, V., \& Mette, A. (2018). Development and evaluation of the psychometric properties of a new measure of athlete burnout: The Athlete Burnout Scale. International Journal of Stress Management, 25, 108-123. https://doi.org/10.1037/str0000083

Kalliath, T.J., O'Driscoll, M.P., Gillespie, D.F., \& Bluedorn, A.C. (2000). A test of the Maslach Burnout Inventory in three samples of healthcare professionals. Work \& Stress, 14, 35-50. https://doi.org/10.1080/026783700417212

Kim, L.E., \& Burić, I. (2020). Teacher self-efficacy and burnout: Determining the directions of prediction through an autoregressive cross-lagged panel model. Journal of Educational Psychology, 112, 1661-1676. https://doi.org/10.1037/edu0000424

Lanza, S.T., Tan, X., \& Bray, B.C. (2013). Latent class analysis with distal outcomes: A flexible model-based approach. Structural Equation Modeling, 20, 1-26. https://doi.org/10.1080/10705511.2013.742377

Laverdière, O., Kealy, D., Ogrodniczuk, J.S., \& Morin, A.J.S. (2018). Psychological health profiles of Canadian psychotherapists: A wake up call on psychotherapists' mental health. Canadian Psychology, 59, 315-322. https://doi.org/10.1037/cap0000159

Leiter, M.P., \& Maslach, C. (2016). Latent burnout profiles: A new approach to understanding the burnout experience. Burnout Research, 3, 89-100. 
https://doi.org/10.1016/j.burn.2016.09.001

Lo, Y., Mendell, N., \& Rubin, D. (2001). Testing the number of components in a normal mixture. Biometrika, 88, 767-778. https://doi.org/10.1093/biomet/88.3.767

Mäkikangas, A., Hyvönen, K., \& Feldt, T. (2017). The energy and identification continua of burnout and work engagement: Developmental profiles over eight years. Burnout Research, 5, 44-54. https://doi.org/10.1016/j.burn.2017.04.002

Marsh, H.W., Hau, K.-T., \& Grayson, D. (2005). Goodness of fit in structural equation models. In A. Maydeu-Olivares \& J.J. McArdle (Eds.), Multivariate applications book series. Contemporary psychometrics (pp. 275-340). Erlbaum.

Marsh, H.W., Lüdtke, O., Trautwein, U., \& Morin, A.J.S. (2009). Latent profile analysis of academic self-concept dimensions: Synergy of person- and variable-centered approaches to the internal/external frame of reference model. Structural Equation Modeling, 16, 1-35. https://doi.org/10.1080/10705510902751010

Maslach, C., Schaufeli, W.B., \& Leiter, M.P. (2001). Job burnout. Annual Review Psychology, 52, 397-422. https://doi.org/10.1146/annurev.psych.52.1.397

Mészáros, V., Ádám, S., Szabó, M., Szigeti, R., \& Urbán, R. (2014). The bifactor model of the Maslach Burnout Inventory-Human Services Survey (MBI-HSS). Stress \& Health, 30, 82-88. https://doi.org/10.1002/smi.2481

Morin, A.J.S., Boudrias, J.-S., Marsh, H.W., Madore, I., \& Desrumaux, P. (2016a). Further reflections on disentengling shape and level effects in person-centered analyses: An illustration exploring the dimensionality of psychological health. Structural Equation Modeling, 23, 438-454. https://doi.org/10.1080/10705511.2015.1116077

Morin, A.J.S., Boudrias, J.-S., Marsh, H.W., McInerney, D.M., Dagenais-Desmarais, V., Madore, I., \& Litalien, D. (2017). Complementary variable- and person-centered approaches to the dimensionality of psychometric constructs: Application to psychological wellbeing at work. 
Journal of Business and Psychology, 32, 395-419. https://doi.org/10.1007/s10869-016-9448-7

Morin, A.J.S., Bujacz, A., \& Gagné, M. (2018). Person-centered methodologies in the organizational sciences: Introduction to the feature topic. Organizational Research Methods, 21, 803-813. https://doi.org/10.1177/1094428118773856

Morin, A.J.S., \& Litalien, D. (2019). Mixture modeling for lifespan developmental research. In Oxford Research Encyclopedia of Psychology. Oxford University Press.

Morin, A.J.S., Maïano, C., Nagengast, B., Marsh, H.W., Morizot, J., \& Janosz, M. (2011). General growth mixture analysis of adolescents' developmental trajectories of anxiety: The impact of untested invariance assumptions on substantive interpretations. Structural Equation Modeling, 18, 613-648. https://doi.org/10.1080/10705511.2011.607714

Morin, A.J.S., Meyer, J.P., Creusier, J., \& Biétry, F. (2016b). Multiple-group analysis of similarity in latent profile solutions. Organizational Research Methods, 19, 231-254. https://doi.org/10.1177/1094428115621148

Muthén, L.K., \& Muthén, B. (2018). Mplus user’s guide. Muthén \& Muthén.

Newman, A., Thanacoody, R., \& Hui, W. (2012). The effects of perceived organizational support, perceived supervisor support and intra-organizational network resources on turnover intentions. Personnel Review, 41, 56-72. https://doi.org/10.1108/00483481211189947

Peterson, U., Bergström, G., Samuelsson, M., Åsberg, M., \& Nygren, Å. (2008). Reflecting peer-support groups in the prevention of stress and burnout. Journal of Advanced Nursing, 63, 506-516. https://doi.org/10.1111/j.1365-2648.2008.04743.x

Peugh, J., \& Fan, X. (2013). Modeling unobserved heterogeneity using latent profile analysis: A Monte Carlo simulation. Structural Equation Modeling, 20, 616-639. https://doi.org/10.1080/10705511.2013.824780

Portoghese, I., Leiter, M.P., Maslach, C., Galletta, M., Porru, F., D'Aloja, E., Finco, G., \& Campagna, M. (2018). Measuring burnout among university students: Factorial validity, 
invariance, and latent profiles of the Italian version of the Maslach Burnout Inventory Student Survey (MBI-SS). Frontiers in Psychology, 9, 2105. https://doi.org/10.3389/fpsyg.2018.02105

Sandrin, É., Gillet, N., Fernet, C., Depint-Rouault, C., Leloup, M., \& Portenard, D. (2019). Effects of workaholism on volunteer firefighters' performance: A moderated mediation model including supervisor recognition and emotional exhaustion. Anxiety, Stress \& Coping, 32, 568-580. https://doi.org/10.1080/10615806.2019.1638683

Schaufeli, W.B., \& Enzmann, D. (1998). The burnout companion to study and research: A critical analysis. Taylor \& Francis.

Shimazu, A., Schaufeli, W.B., Kamiyama, K., \& Kawakami, N. (2015). Workaholism vs. work engagement. International Journal of Behavioral Medicine, 22, 18-23. https://doi.org/10.1007/s12529-014-9410-х

Shirom, A., \& Melamed, S. (2006). A comparison of the construct validity of two burnout measures in two groups of professionals. International Journal of Stress Management, 13, 176-200. https://doi.org/10.1037/1072-5245.13.2.176

Skaalvik, E.M., \& Skaalvik, S. (2010). Teacher self-efficacy and teacher burnout: A study of relations. Teaching and Teacher Education, 26, 1059-1069. https://doi.org/10.1016/j.tate.2009.11.001

Sonnentag, S., \& Fritz, C. (2015). Recovery from job stress: The stressor- detachment model as an integrative framework. Journal of Organizational Behavior, 36, S72-S103. https://doi.org/10.1002/job.1924

Szigeti, R., Balázs, N., Bikfalvi, R., \& Urbán, R. (2017). Burnout and depressive symptoms in teachers: Factor structure and construct validity of the Maslach Burnout InventoryEducators among elementary and secondary school teachers in Hungary. Stress \& Health, 33, 530-539. https://doi.org/10.1002/smi.2737 
Figure 1. Final 5-Profile Solution

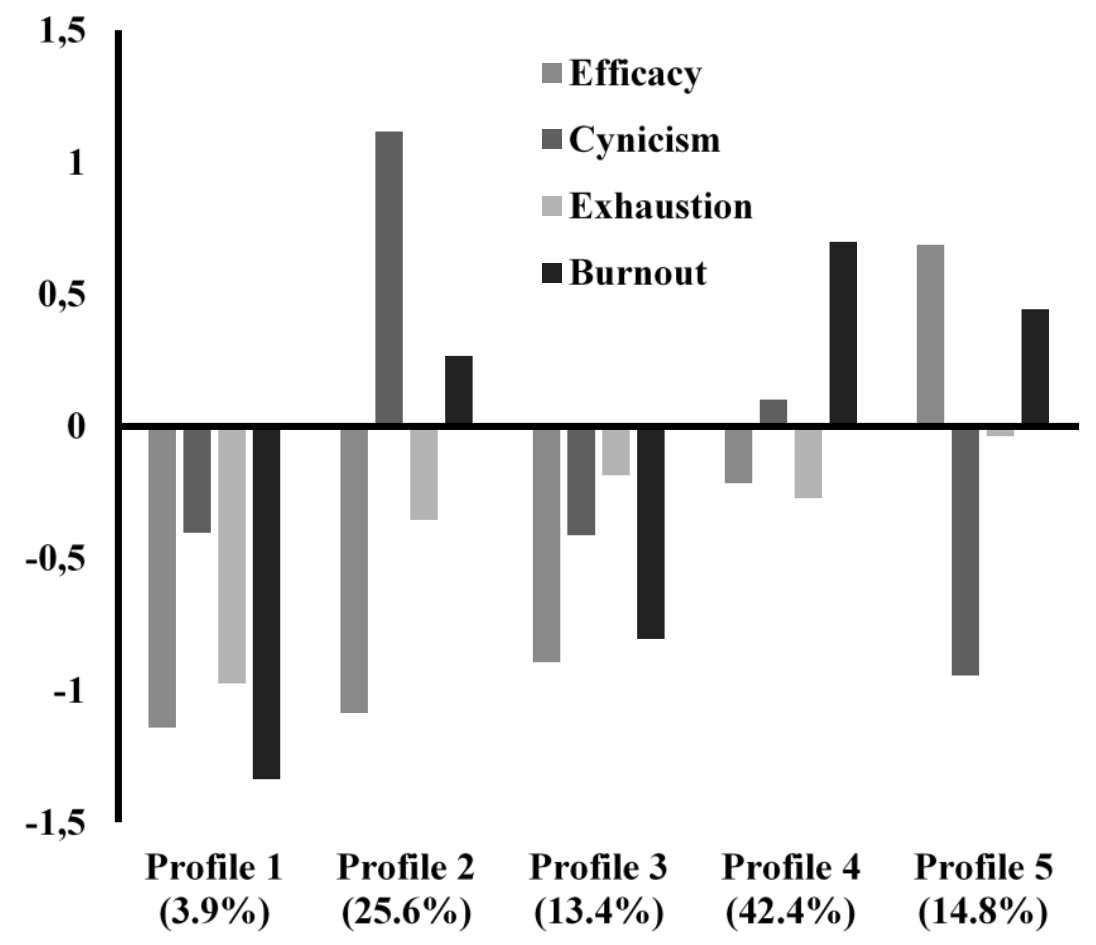

Note. Indicators are factor scores with a mean of 0 and a standard deviation of 1 ; Profiles 1 (Very Low Burnout Risk), 2 (Mentally Distanced), 3 (Low Burnout Risk), 4 (High Burnout Risk), and 5 (Moderately High Burnout Risk). 


\section{Table 1}

Parameter Estimates from the Preliminary Measurement Models (Burnout, Study 1)

\begin{tabular}{|c|c|c|c|c|c|c|c|c|c|c|c|c|c|c|}
\hline & CFA & & & & Bifactor- & & & & & Alternati & Bifa & -CFA & & \\
\hline Items & $\begin{array}{c}\mathrm{PE} \\
\lambda\end{array}$ & $\begin{array}{c}\text { Cynicism } \\
\lambda\end{array}$ & $\begin{array}{c}\text { Exhaustion } \\
\lambda\end{array}$ & $\delta$ & $\begin{array}{c}\text { G-factor } \\
\lambda\end{array}$ & $\begin{array}{l}\text { S-PE } \\
\lambda\end{array}$ & $\begin{array}{c}\text { S-Cynicism } \\
\lambda\end{array}$ & $\begin{array}{c}\text { S- Exhaustion } \\
\lambda\end{array}$ & $\delta$ & $\begin{array}{c}\text { G-factor } \\
\lambda\end{array}$ & $\begin{array}{c}\mathrm{PE} \\
\lambda\end{array}$ & $\begin{array}{c}\text { S-Cynicism } \\
\lambda\end{array}$ & $\begin{array}{c}\text { S- Exhaustion } \\
\lambda\end{array}$ & $\delta$ \\
\hline$\overline{\mathrm{PE}}$ & & & & & & & & & & & & & & \\
\hline 1 & .71 & & & .50 & -.11 & .71 & & & .48 & & .71 & & & .50 \\
\hline 2 & .66 & & & .56 & .00 & .66 & & & .56 & & .68 & & & .54 \\
\hline 3 & .68 & & & .54 & .03 & .68 & & & .54 & & .67 & & & .56 \\
\hline 4 & .58 & & & .67 & .02 & .58 & & & .67 & & .58 & & & .67 \\
\hline 5 & .40 & & & .84 & .05 & .40 & & & .84 & & .39 & & & .85 \\
\hline 6 & .35 & & & .88 & .16 & .35 & & & .85 & & .35 & & & .88 \\
\hline Cynicis & & & & & & & & & & & & & & \\
\hline 1 & & .37 & & .86 & .30 & & .21 & & .86 & .31 & & .20 & & .86 \\
\hline 2 & & .83 & & .31 & .39 & & .82 & & .17 & .39 & & .83 & & .17 \\
\hline 3 & & .84 & & .29 & .47 & & .63 & & .38 & .47 & & .63 & & .38 \\
\hline 4 & & .39 & & .84 & .08 & & .44 & & .80 & .08 & & .44 & & .80 \\
\hline Exhaus & & & & & & & & & & & & & & \\
\hline 1 & & & .83 & .31 & .81 & & & .26 & .28 & .79 & & & .28 & .29 \\
\hline 2 & & & .77 & .40 & .75 & & & .36 & .31 & .73 & & & .43 & .28 \\
\hline 3 & & & .77 & .40 & .78 & & & .00 & .40 & .78 & & & .03 & .39 \\
\hline 4 & & & .88 & .23 & .86 & & & .11 & .25 & .85 & & & .15 & .25 \\
\hline 5 & & & .80 & .37 & .87 & & & -.27 & .18 & .87 & & & -.19 & .22 \\
\hline$\omega$ & .74 & .72 & .91 & & .81 & .74 & .67 & .41 & & .89 & .74 & .67 & .45 & \\
\hline
\end{tabular}

Note. CFA $=$ Confirmatory factor analyses; $\mathrm{PE}=$ Professional efficacy; $\mathrm{G}=$ Global factor (bifactor); $\mathrm{S}=$ Specific factor (bifactor); $\lambda$ : Loading; $\delta$ : Uniqueness; $\omega$ : Omega; non-significant parameters $(p \geq .05)$ marked in italics. 
Table 2

Correlations between Variables

\begin{tabular}{|c|c|c|c|c|c|c|c|c|}
\hline Variable & 1 & 2 & 3 & 4 & 5 & 6 & 7 & 8 \\
\hline \multicolumn{9}{|l|}{ Study 1: Latent Correlations } \\
\hline 1.Burnout G-factor & - & & & & & & & \\
\hline 2.Professional efficacy & .07 & - & & & & & & \\
\hline 3.Cynicism S-factor & .00 & -.08 & - & & & & & \\
\hline 4.Exhaustion S-factor & .00 & -.23 & .00 & - & & & & \\
\hline 5.Organizational recognition & $-.41 * *$ & $-.22 *$ & -.05 & .08 & - & & & \\
\hline 6.Supervisor recognition & $-.49 * *$ & $-.22 *$ & .02 & .07 & $.61 * *$ & - & & \\
\hline 7.Colleagues recognition & $-.27 * *$ & $-.21^{*}$ & $-.15^{*}$ & -.11 & $.35^{* *}$ & $.33^{* *}$ & - & \\
\hline 8.Job satisfaction & $-.64 * *$ & -.12 & -.02 & .11 & $.43 * *$ & $.43^{* *}$ & .12 & - \\
\hline \multicolumn{9}{|c|}{ Study 2: Factor Score Correlations } \\
\hline 1.Burnout G-factor ${ }^{1}$ & - & & & & & & & \\
\hline 2.Professional efficacy ${ }^{1}$ & $.35^{* *}$ & - & & & & & & \\
\hline 3.Cynicism $S$-factor ${ }^{1}$ & .00 & $-.47 * *$ & - & & & & & \\
\hline 4.Exhaustion $S$-factor ${ }^{1}$ & .00 & $.10 * *$ & .00 & - & & & & \\
\hline 5.Organizational recognition ${ }^{1}$ & $-.32 * *$ & $-.18 * *$ & .03 & $-.18 * *$ & - & & & \\
\hline 6.Supervisor recognition ${ }^{1}$ & $-.35 * *$ & $-.20 * *$ & -.01 & $-.27 * *$ & $.69^{* *}$ & - & & \\
\hline 7.Colleagues recognition ${ }^{1}$ & $-.16^{* *}$ & $-.22 * *$ & $.10^{* *}$ & $-.23 * *$ & $.20 * *$ & $.25^{* *}$ & - & \\
\hline 8.Job satisfaction & $-.28 * *$ & $-.23 * *$ & $.10^{* *}$ & $-.33 * *$ & $.49 * *$ & $.47 * *$ & $.19^{* *}$ & - \\
\hline
\end{tabular}

Note. ${ }^{*} p<.05 ; * * p<.01 ;{ }^{1}$ : indicators are factor scores with a standard deviation of 1 and a mean of $0 ; \mathrm{G}=$ Global factor (bifactor); $\mathrm{S}=$ Specific factor (bifactor). 


\section{Table 4}

Latent Profile Analyses (Study 2)

\begin{tabular}{|c|c|c|c|c|c|c|c|c|c|c|}
\hline Model & $\mathrm{LL}$ & $\# \mathrm{fp}$ & Scaling & AIC & CAIC & $\mathrm{BIC}$ & $\mathrm{ABIC}$ & Entropy & aLMR & BLRT \\
\hline \multicolumn{11}{|c|}{ Unconditional Latent Profile Analyses } \\
\hline 1 Profile & -3381.41 & 8 & 1.08 & 6778.83 & 6822.69 & 6814.69 & 6789.29 & $\mathrm{Na}$ & $\mathrm{Na}$ & $\mathrm{Na}$ \\
\hline 2 Profiles & -3295.57 & 17 & 1.14 & 6625.14 & 6718.35 & 6701.35 & 6647.37 & .63 & $<.001$ & $<.001$ \\
\hline 3 Profiles & -3194.77 & 26 & 1.23 & 6441.55 & 6584.11 & 6558.11 & 6475.56 & .72 & $<.001$ & $<.001$ \\
\hline 4 Profiles & -3128.56 & 35 & 1.13 & 6327.12 & 6519.03 & 6484.03 & 6372.90 & .73 & .02 & $<.001$ \\
\hline 5 Profiles & -3081.11 & 44 & 1.18 & 6250.22 & 6491.47 & 6447.47 & 6307.77 & .76 & .16 & $<.001$ \\
\hline 6 Profiles & -3046.15 & 53 & 1.13 & 6198.30 & 6488.90 & 6435.90 & 6267.63 & .79 & .16 & $<.001$ \\
\hline 7 Profiles & -3014.66 & 62 & 1.14 & 6153.32 & 6493.27 & 6431.27 & 6234.42 & .79 & .19 & $<.001$ \\
\hline 8 Profiles & -2980.61 & 71 & 1.04 & 6103.22 & 6492.52 & 6421.52 & 6196.09 & .81 & .00 & $<.001$ \\
\hline \multicolumn{11}{|c|}{ Models with Demographic Variables } \\
\hline Null Effect & -5854.76 & 48 & 2.43 & 11805.52 & 12068.70 & 12020.70 & 11868.30 & .76 & $\mathrm{Na}$ & $\mathrm{Na}$ \\
\hline $\begin{array}{l}\text { Effects Freely Estimated } \\
\text { Models with Recognition }\end{array}$ & -5832.66 & 80 & 1.87 & 11825.33 & 12263.97 & 12183.97 & 11929.97 & .77 & $\mathrm{Na}$ & $\mathrm{Na}$ \\
\hline Null Effect & -3081.11 & 4 & 1.00 & 6170.22 & 6192.15 & 6188.15 & 6175.45 & .76 & $\mathrm{Na}$ & $\mathrm{Na}$ \\
\hline Effects Freely Estimated & -3045.00 & 16 & 1.01 & 6121.99 & 6209.72 & 6193.72 & 6142.92 & .77 & $\mathrm{Na}$ & $\mathrm{Na}$ \\
\hline
\end{tabular}

Note: LL: LogLikelihood; \#fp: Free parameters; Scaling: Scaling correction; AIC: Akaïke Information Criteria; CAIC: Constant AIC; BIC: Bayesian

Information Criteria; ABIC: Sample-size adjusted BIC; aLMR: Adjusted Lo-Mendel-Rubin likelihood ratio test; BLRT: Bootstrap Likelihood Ratio Test. 


\section{Table 5}

Multivariate Associations between Recognition and Profile Membership (Study 2)

\begin{tabular}{|c|c|c|c|c|c|c|c|c|c|c|}
\hline \multirow[b]{2}{*}{ Source of Recognition } & \multicolumn{2}{|c|}{ Profile 1 vs 5} & \multicolumn{2}{|c|}{ Profile 2 vs 5} & \multicolumn{2}{|c|}{ Profile 3 vs 5} & \multicolumn{2}{|c|}{ Profile 4 vs 5} & \multicolumn{2}{|c|}{ Profile 1 vs 4} \\
\hline & Coef. (SE) & OR & Coef. (SE) & OR & Coef. (SE) & OR & Coef. (SE) & OR & Coef. (SE) & OR \\
\hline Organizational Recognition & $0.36(.34)$ & 1.43 & $0.36(.24)$ & 1.43 & $0.14(.29)$ & 1.14 & $0.06(.25)$ & 1.06 & $0.30(.28)$ & 1.35 \\
\hline Supervisor Recognition & $0.52(.32)$ & 1.69 & $0.24(.21)$ & 1.27 & $0.89(.28)^{* *}$ & 2.44 & $0.18(.21)$ & 1.19 & $0.35(.29)$ & 1.42 \\
\hline \multirow[t]{2}{*}{ Colleagues Recognition } & $1.26(.33) * *$ & 3.53 & $0.64(.18) * *$ & 1.90 & $0.55(.22)^{*}$ & 1.73 & $0.41(.15)^{* *}$ & 1.50 & $0.86(.31)^{* *}$ & 2.35 \\
\hline & \multicolumn{2}{|c|}{ Profile 2 vs 4} & \multicolumn{2}{|c|}{ Profile 3 vs 4} & \multicolumn{2}{|c|}{ Profile 1 vs 3} & \multicolumn{2}{|c|}{ Profile 2 vs 3} & \multicolumn{2}{|c|}{ Profile 1 vs 2} \\
\hline Source of Recognition & Coef. (SE) & OR & Coef. (SE) & OR & Coef. (SE) & $\mathrm{OR}$ & Coef. (SE) & $\mathrm{OR}$ & Coef. (SE) & OR \\
\hline Organizational Recognition & $0.30(.19)$ & 1.35 & $0.08(.23)$ & 1.08 & $0.23(.33)$ & 1.25 & $0.23(.23)$ & 1.25 & $0.00(.29)$ & 1.00 \\
\hline Supervisor Recognition & $0.06(.18)$ & 1.06 & $0.71(.24) * *$ & 2.04 & $-0.37(.35)$ & 0.69 & $-0.65(.25)^{* *}$ & 0.52 & $0.29(.30)$ & 1.33 \\
\hline Colleagues Recognition & $0.23(.16)$ & 1.26 & $0.14(.19)$ & 1.15 & $0.72(.34) * *$ & 2.05 & $0.09(.20)$ & 1.10 & $0.62(.31)^{*}$ & 1.86 \\
\hline
\end{tabular}

Note. ${ }^{*} p<.05 ; * *<.01 ;$ SE: Standard error of the coefficient; OR: Odds ratio; coefficients and OR reflect the relations between recognition and the likelihood of membership into the first listed profile relative to the second one; organizational, supervisor, and colleagues recognition are factor scores with a standard deviation of 1 and a mean of 0; Profiles 1 (Very Low Burnout Risk), 2 (Mentally Distanced), 3 (Low Burnout Risk), 4 (High Burnout Risk), and 5 (Moderately High Burnout Risk). 
Online Supplemental Materials for:

Complementary Variable- and Person-Centered Approaches to the Dimensionality of Burnout

Among Fire Station Workers

Table S1

Standardized Factor Loadings ( $\lambda$ ), Uniquenesses $(\delta)$, and Correlations from the CFA Solution

(Recognition, Study 1)

\begin{tabular}{|c|c|c|c|c|}
\hline Items & $\begin{array}{c}\text { Organizational } \\
\text { recognition } \\
\lambda\end{array}$ & $\begin{array}{c}\text { Supervisor } \\
\text { recognition } \\
\lambda\end{array}$ & $\begin{array}{c}\text { Colleagues } \\
\text { recognition } \\
\lambda\end{array}$ & $\delta$ \\
\hline \multicolumn{5}{|l|}{ Organizational recognition } \\
\hline Item 1 & .54 & & & .71 \\
\hline Item 2 & .66 & & & .57 \\
\hline Item 3 & .76 & & & .43 \\
\hline Item 4 & .81 & & & .35 \\
\hline Item 5 & .52 & & & .73 \\
\hline \multicolumn{5}{|l|}{ Supervisor recognition } \\
\hline Item 1 & & .82 & & .32 \\
\hline Item 2 & & .88 & & .22 \\
\hline Item 3 & & .87 & & .25 \\
\hline Item 4 & & .71 & & .49 \\
\hline Item 5 & & .79 & & .38 \\
\hline \multicolumn{5}{|l|}{ Colleagues recognition } \\
\hline Item 1 & & & .75 & .44 \\
\hline Item 2 & & & .92 & .16 \\
\hline Item 3 & & & .92 & .16 \\
\hline Item 4 & & & .84 & .29 \\
\hline$\omega$ & .79 & .91 & .92 & \\
\hline Correlations & 1 & 2 & 3 & \\
\hline 1. Organizational recognition & - & & & \\
\hline 2. Supervisor recognition & .61 & - & & \\
\hline 3. Colleagues recognition & .35 & .33 & - & \\
\hline
\end{tabular}

Note. $\lambda$ : Factor loading; $\delta$ : Item uniqueness; $\omega$ : Omega coefficient of model-based composite reliability. 


\section{Preliminary Measurement Models (Study 2)}

\section{Preliminary Measurement Models: Estimation}

Preliminary analyses conducted in Study 2 matched the analyses conducted in Study 1 (as described in the main manuscript). In addition, tests of measurement invariance across the samples used in both studies were also realized. More precisely, we assessed (Millsap, 2011): (1) configural invariance; (2) weak invariance (loadings); (3) strong invariance (loadings and intercepts); (4) strict invariance (loadings, intercepts, and uniquenesses); (5) invariance of the latent variance-covariance matrix (loadings, intercepts, uniquenesses, and latent variances and covariances); and (6) latent means invariance (loadings, intercepts, uniquenesses, latent variances and covariances, and latent means). Factor scores were saved from the most invariant of those models. Like the chi-square, chi-square difference tests present a known sensitivity to sample size and minor model misspecifications so that recent studies suggest complementing this information with changes in CFIs and RMSEAs (Chen, 2007; Cheung \& Rensvold, 2002) in the context of tests of measurement invariance. A $\Delta C F I$ of .010 or less, a $\triangle \mathrm{TLI}$ of .010 or less, and a $\triangle \mathrm{RMSEA}$ of .015 or less between a more restricted model and the previous one support the invariance hypothesis.

\section{Preliminary Measurement Models: Results}

The goodness-of-fit results from all models are reported in Table S2. These results clearly support the adequacy of the alternative bifactor-CFA models underlying the burnout measure and it superiority relative to the CFA solution. This solution was thus retained for tests of measurement invariance. The results from these tests, also reported in Table S2, supported the configural and weak invariance of the model. However, neither strong, nor strict, invariance was supported, leading us to consider models of partial invariance in which equality constraints had to be relaxed on the intercepts and uniquenesses of only two items. These models of partial invariance were supported by the data, as well as the next model of invariance of the latent variances and covariances. However, the last model of latent mean invariance was not supported by the data, leading us to extract factor scores from the model of latent variance-covariance invariance. When looking more specifically at the latent means estimated as part of this model: (a) latent means on the reduced professional efficacy factors were .862 SD higher in Study 2 relative to Study 1; (b) means on the burnout G-factor were .54 SD lower 
in Study 2 relative to Study 1; (c) means on the cynicism S-factor were non-statistically different across Studies; and (d) means on the emotional exhaustion S-factor were .55 SD higher in Study 2 relative to Study 1.

Parameter estimates from this final model are reported in Table S3 and revealed a well-defined GFactor across samples $(\omega=.84)$ with strong positive loadings from the cynicism $\left(\lambda=.55\right.$ to $.71 ; M_{|\lambda|}=$ $.64)$ and emotional exhaustion $\left(\lambda .=30\right.$ to $\left..40 ; M_{|\lambda|}=.35\right)$ items. Over and above this G-Factor, items associated with the cynicism $\left(\lambda=-.24\right.$ to $\left..67 ; M_{|\lambda|}=.31 ; \omega=.46\right)$ and emotional exhaustion $(\lambda=.65$ to $\left..81 ; M_{|\lambda|}=.71 ; \omega=.87\right) \mathrm{S}$-factors both retained some specificity. In both samples, the reduced professional efficacy factor was also well-defined $\left(\lambda=.39\right.$ to $.71 ; M_{|\lambda|}=.52 ; \omega=.64$ in Sample 1 and .70 in Sample 2).

Finally, the results also support the adequacy of the model underlying the correlated predictor measures. The tests of measurement invariance conducted on responses to these correlated predictor measures revealed support for a model of configural, weak, strong, and strict invariance, as well as the invariance of the correlated uniquenesses, latent variances and covariances, and latent means across samples. Parameter estimates from this final model are reported in Table S4 and reveal well-defined factors for all constructs considered here: (a) organizational recognition $\left(\lambda=.52\right.$ to $.78 ; M_{|\lambda|}=.65 ; \omega=$ .79 ); (b) supervisor recognition ( $\lambda=.76$ to $.89 ; M_{|\lambda|}=.85 ; \omega=.93$ ); and (c) colleagues recognition $(\lambda=$ 73 to $\left..90 ; M_{|\lambda|}=.84 ; \omega=.91\right)$.

\section{References used in this supplement}

Chen, F.F. (2007). Sensitivity of goodness of fit indexes to lack of measurement. Structural Equation Modeling, 14, 464-504. https://doi.org/10.1080/10705510701301834

Cheung, G.W., \& Rensvold, R.B. (2002). Evaluating goodness-of fit indexes for testing measurement invariance. Structural Equation Modeling, 9, 233-255.

https://doi.org/10.1207/S15328007SEM0902_5

Millsap, R. (2011). Statistical approaches to measurement invariance. Taylor \& Francis. 


\section{Table S2}

Goodness-of-Fit Statistics of the Preliminary Measurement Models

\begin{tabular}{|c|c|c|c|c|c|c|c|c|c|c|}
\hline Description & $\chi^{2}(d f)$ & CFI & TLI & RMSEA & $90 \% \mathrm{CI}$ & $\mathrm{CM}$ & $\Delta \chi^{2}(d f)$ & $\Delta \mathrm{CFI}$ & $\Delta \mathrm{TLI}$ & $\triangle \mathrm{RMSEA}$ \\
\hline \multicolumn{11}{|l|}{ Study 2: Burnout } \\
\hline CFA & $312.19(87)^{*}$ & .91 & .89 & .06 & {$[.06 ; .07]$} & - & - & - & - & - \\
\hline Bifactor-CFA & $235.16(75)^{*}$ & .93 & .91 & .06 & {$[.05 ; .07]$} & - & - & - & - & - \\
\hline Alternative bifactor-CFA & $216.76(78)^{*}$ & .94 & .92 & .05 & {$[.04 ; .06]$} & - & - & - & - & - \\
\hline \multicolumn{11}{|l|}{ Study 2: Correlated Predictors } \\
\hline CFA & $238.44(74)^{*}$ & .96 & .96 & .06 & {$[.05 ; .07]$} & - & - & - & - & - \\
\hline \multicolumn{11}{|l|}{ Multi-Group Models: Burnout } \\
\hline M1. Configural invariance & $386.13(156)^{*}$ & .93 & .91 & .06 & {$[.05 ; .06]$} & - & - & - & - & - \\
\hline M2. Weak invariance & $416.73(176)^{*}$ & .93 & .92 & .06 & {$[.05 ; .06]$} & M1 & $31.67(20)$ & -.003 & +.007 & -.002 \\
\hline M3. Strong invariance & $495.52(187)^{*}$ & .91 & .90 & .06 & {$[.05 ; .07]$} & M2 & $84.86(11)^{*}$ & -.019 & -.017 & +.006 \\
\hline M4. Partial strong invariance & $437.03(185)^{*}$ & .93 & .92 & .06 & {$[.05 ; .06]$} & M2 & $20.27(9)$ & -.003 & .000 & .000 \\
\hline M5. Strict invariance & $503.19(200)^{*}$ & .91 & .91 & .06 & {$[.05 ; .06]$} & M4 & $59.85(15) *$ & -.015 & -.009 & +.003 \\
\hline M6. Partial strict invariance & $459.43(198)^{*}$ & .93 & .92 & .05 & {$[.05 ; .06]$} & M4 & $24.13(13)$ & -.003 & +.003 & -.001 \\
\hline M7. Latent variance-covariance invariance & $474.25(202)^{*}$ & .92 & .92 & .06 & {$[.05 ; .06]$} & M6 & $13.33(4)^{*}$ & -.003 & -.002 & +.001 \\
\hline M8. Latent means invariance & $604.58(206)^{*}$ & .89 & .88 & .07 & {$[.06 ; .07]$} & M7 & $174.13(4) *$ & -.036 & -.035 & +.011 \\
\hline \multicolumn{11}{|l|}{ Multi-Group Models: Correlated Predictors } \\
\hline M1. Configural invariance & $364.57(148)^{*}$ & .97 & .96 & .06 & {$[.05 ; .06]$} & - & - & - & - & - \\
\hline M2. Weak invariance & $379.27(159)^{*}$ & .96 & .96 & .06 & {$[.05 ; .06]$} & M1 & $12.91(11)$ & -.001 & +.002 & -.002 \\
\hline M3. Strong invariance & $439.93(170)^{*}$ & .96 & .95 & .06 & {$[.05 ; .07]$} & M2 & $64.06(11)^{*}$ & -.008 & -.006 & +.002 \\
\hline M4. Strict invariance & $464.18(184)^{*}$ & .96 & .96 & .06 & {$[.05 ; .07]$} & M3 & $26.79(14)$ & -.001 & +.002 & -.001 \\
\hline M5. Latent variance-covariance invariance & $480.28(190)^{*}$ & .95 & .96 & .06 & {$[.05 ; .07]$} & M4 & $16.21(6)$ & -.002 & .000 & .000 \\
\hline M6. Latent means invariance & $495.70(193)^{*}$ & .95 & .95 & .06 & {$[.05 ; .07]$} & M5 & $15.93(4)^{*}$ & -.002 & -.001 & +.001 \\
\hline
\end{tabular}

Note. $* p<.01 ; \chi^{2}$. Robust chi-square test of exact fit; $d f$ : Degrees of freedom; CFI: Comparative fit index; TLI: Tucker-Lewis index; RMSEA: Root mean square error of approximation; $90 \% \mathrm{CI}$ : $90 \%$ confidence interval; CM: Comparison model; $\Delta$ : Change in fit relative to the CM. 


\section{Table S3}

Standardized Factor Loadings $(\lambda)$ and Uniquenesses $(\delta)$ from the Most Invariant Alternative BifactorCFA Solution (Burnout)

\begin{tabular}{|c|c|c|c|c|c|}
\hline Items & $\begin{array}{c}\text { G-factor } \\
\lambda\end{array}$ & $\begin{array}{c}\text { Professional } \\
\text { Efficacy } \\
\lambda\end{array}$ & $\begin{array}{c}\text { S-Cynicism } \\
\lambda\end{array}$ & $\begin{array}{c}\text { S-Exhaustion } \\
\lambda\end{array}$ & $\delta$ \\
\hline \multicolumn{6}{|c|}{ Professional } \\
\hline \multicolumn{6}{|c|}{ Efficacy } \\
\hline Item 1 & & (44/.59 & & & $.80 / .65$ \\
\hline Item 2 & & $.54 / .71$ & & & $.71 / .49$ \\
\hline Item 3 & & .54 & & & .71 \\
\hline Item 4 & & .51 & & & .74 \\
\hline Item 5 & & .39 & & & .85 \\
\hline Item 6 & & .44 & & & .81 \\
\hline \multicolumn{6}{|l|}{ Cynicism } \\
\hline Item 1 & .68 & & -.24 & & .48 \\
\hline Item 2 & .60 & & .16 & & .61 \\
\hline Item 3 & .71 & & .67 & & .04 \\
\hline Item 4 & .55 & & -.16 & & .67 \\
\hline \multicolumn{6}{|l|}{ Exhaustion } \\
\hline Item 1 & .31 & & & .75 & .35 \\
\hline Item 2 & .30 & & & .69 & .44 \\
\hline Item 3 & .35 & & & .68 & .42 \\
\hline Item 4 & .38 & & & .81 & 20 \\
\hline Item 5 & .40 & & & .65 & .42 \\
\hline$\omega$ & .84 & 要. .70 & .46 & .87 & \\
\hline \multicolumn{6}{|c|}{$\begin{array}{l}\text { Note. Standardized parameter estimates found to differ across samples are indicated by / with } \\
\text { parameters estimates from Study } 1 \text { sample on the left hand side of the / symbol, and those from Study } \\
2 \text { sample on the right hand side; } \mathrm{G}=\text { Global factor estimated as part of a bifactor model; } \mathrm{S}=\text { Specific } \\
\text { factor estimated as part of a bifactor model; } \lambda \text { : Factor loading; } \delta \text { : Item uniqueness; } \omega \text { : Omega } \\
\text { coefficient of model-based composite reliability; non-significant parameters }(p \geq .05) \text { are marked in } \\
\text { italics. }\end{array}$} \\
\hline
\end{tabular}




\section{Table S4}

Standardized Factor Loadings ( $\lambda)$, Uniquenesses $(\delta)$, and Correlations from the Most Invariant CFA

Solution (Recognition)

\begin{tabular}{|c|c|c|c|c|}
\hline Items & $\begin{array}{c}\text { Organizational } \\
\text { recognition } \\
\lambda\end{array}$ & $\begin{array}{c}\text { Supervisor } \\
\text { recognition } \\
\lambda\end{array}$ & $\begin{array}{c}\text { Colleagues } \\
\text { recognition } \\
\lambda\end{array}$ & $\delta$ \\
\hline \multicolumn{5}{|l|}{ Organizational recognition } \\
\hline Item 1 & .58 & & & .66 \\
\hline Item 2 & .67 & & & .55 \\
\hline Item 3 & .71 & & & .50 \\
\hline Item 4 & .78 & & & .39 \\
\hline Item 5 & .52 & & & .73 \\
\hline \multicolumn{5}{|l|}{ Supervisor recognition } \\
\hline Item 1 & & .87 & & .25 \\
\hline Item 2 & & .89 & & .22 \\
\hline Item 3 & & .87 & & .24 \\
\hline Item 4 & & .76 & & .42 \\
\hline Item 5 & & .85 & & .29 \\
\hline \multicolumn{5}{|l|}{ Colleagues recognition } \\
\hline Item 1 & & & .73 & .47 \\
\hline Item 2 & & & .90 & .19 \\
\hline Item 3 & & & .90 & .19 \\
\hline Item 4 & & & .82 & .32 \\
\hline$\omega$ & .79 & .93 & .91 & \\
\hline Correlations & 1 & 2 & 3 & \\
\hline 1. Organizational recognition & - & & & \\
\hline 2. Supervisor recognition & .62 & - & & \\
\hline 3. Colleagues recognition & .22 & .25 & - & \\
\hline
\end{tabular}

Note. $\lambda$ : Factor loading; $\delta$ : Item uniqueness; $\omega$ : Omega coefficient of model-based composite reliability. 


\section{Figure S1}

Elbow Plot of the Value of the Information Criteria for Solutions Including Different Numbers of Latent Profiles (Study 2)

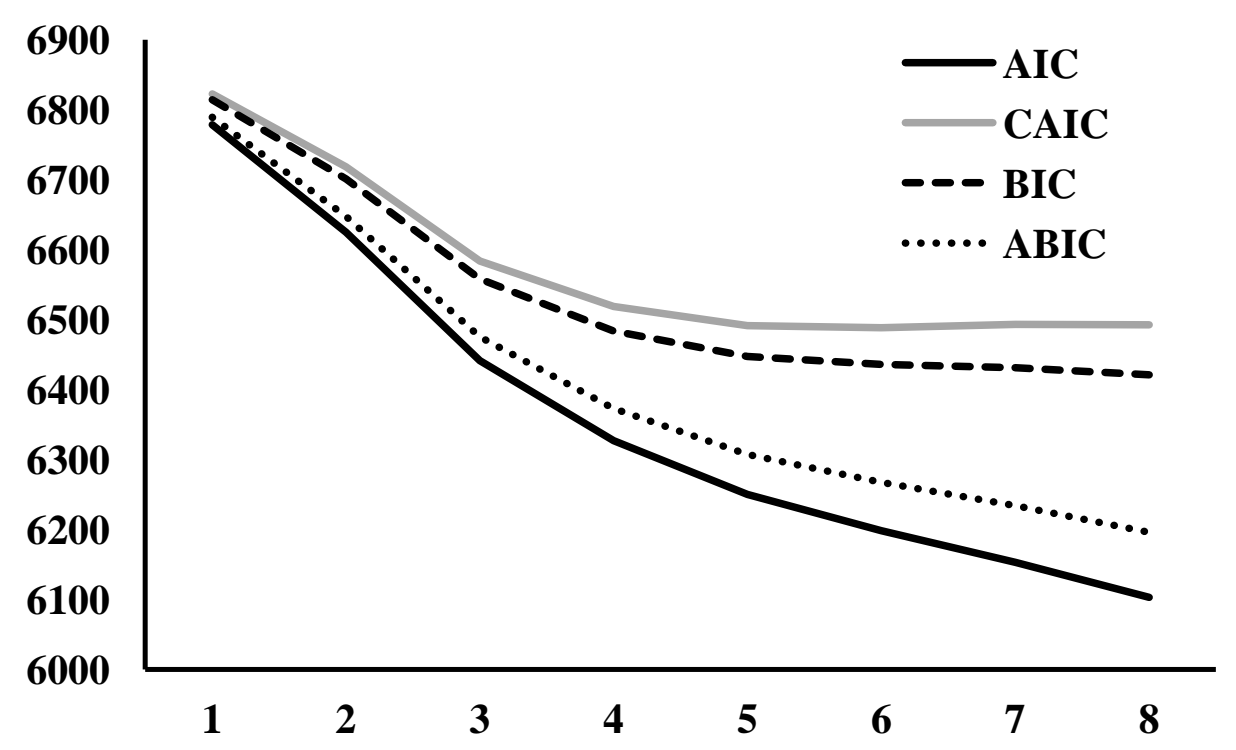


Supplements for Burnout Dimensionality and Profiles S8

\section{Table S5}

Classification Accuracy: Average Probability of Membership into Each Latent Profile (Column) as a Function of the Most Likely Profile Membership (Row)

\begin{tabular}{|c|c|c|c|c|c|}
\hline \multirow{2}{*}{ Sample 2} & \multirow[t]{2}{*}{ Profile 1} & \multirow[t]{2}{*}{ Profile 2} & \multirow[t]{2}{*}{ Profile 3} & \multirow[t]{2}{*}{ Profile 4} & \multirow[t]{2}{*}{ Profile 5} \\
\hline & & & & & \\
\hline Profile 1 & .94 & .00 & .06 & .00 & .00 \\
\hline Profile 2 & .00 & .84 & .02 & .13 & .00 \\
\hline Profile 3 & .01 & .02 & .84 & .09 & .05 \\
\hline Profile 4 & .00 & .08 & .02 & .83 & .07 \\
\hline Profile 5 & .00 & .00 & .03 & .12 & .85 \\
\hline
\end{tabular}

